\title{
High-Frequency Modeling of a Three-Winding Power Transformer Using Sweep Frequency Response Analysis
}

\author{
Yeunggurl Yoon ${ }^{1}{ }^{\mathbb{D}}$, Yongju Son ${ }^{1}$, Jintae $\mathrm{Cho}^{2}$, SuHyeong Jang ${ }^{3}$, Young-Geun Kim ${ }^{3}$ and Sungyun Choi ${ }^{1, * \mathbb{C}}$ \\ 1 School of Electrical Engineering, Korea University, 145 Anam-ro, Seongbuk-gu, Seoul 02841, Korea; \\ tigeryoon98@korea.ac.kr (Y.Y.); 93yjson@korea.ac.kr (Y.S.) \\ 2 Korea Electric Power Research Institute, 105 Munji-ro, Yooseong-gu, Daejeon 34056, Korea; \\ jintae.cho@kepco.co.kr \\ 3 LS Electric Co., Ltd., 127 LS-ro, Dongan-gu, Anyang 14119, Korea; suhjang@lselectric.co.kr (S.J.); \\ youngk@ls-electric.com (Y.-G.K.) \\ * Correspondence: sungyun@korea.ac.kr
}

Citation: Yoon, Y.; Son, Y.; Cho, J.; Jang, S.; Kim, Y.-G.; Choi, S.

High-Frequency Modeling of a

Three-Winding Power Transformer Using Sweep Frequency Response Analysis. Energies 2021, 14, 4009. https://doi.org/10.3390/en14134009

Academic Editors: Huseyin Hiziroglu and Sérgio Cruz

Received: 7 May 2021

Accepted: 1 July 2021

Published: 3 July 2021

Publisher's Note: MDPI stays neutral with regard to jurisdictional claims in published maps and institutional affiliations.

Copyright: (C) 2021 by the authors. Licensee MDPI, Basel, Switzerland. This article is an open access article distributed under the terms and conditions of the Creative Commons Attribution (CC BY) license (https:// creativecommons.org/licenses/by/ $4.0 /)$

\begin{abstract}
A power transformer is an essential device for stable and reliable power transfer to customers. Therefore, accurate modeling of transformers is required for simulation-based analysis with the model. The paper proposes an efficient and straightforward parameter estimation of power transformers based on sweep frequency response analysis (SFRA) test data. The method first develops a transformer model consisting of repetitive RLC sections and mutual inductances and then aligns the simulated SFRA curve with the measured one by adjusting parameters. Note that this adjustment is based on individual parameter impacts on the SFRA curve. After aligning the two curves, the final transformer model can be obtained. In this paper, actual single-phase, three-winding transformer model parameters were estimated based on field SFRA data, showing that SFRA curves simulated from the estimated model are consistent with the measured data.
\end{abstract}

Keywords: FRA; parameter estimation; power transformer; SFRA; transformer

\section{Introduction}

Power systems transmit electric energy to consumers through essential devices. For safety, power system operators must inspect the devices before connecting them to the system using computer simulations. Particularly, the power transformer is an essential component that steps up or down voltages for efficient and safe power transmissions. Therefore, there have been many studies on modeling and model parameter estimation of the power transformers. The power transformer model primarily has turn ratios and includes loss components, if necessary. However, this model presents limited information about the characteristics of a power transformer. A high-frequency transformer model reflects the structural and physical characteristics [1]. As described in [2-14], the model comprises of repetitive RLC sections and is called a lumped parameter model or ladder circuit because its structure looks like a ladder. A single-winding transformer model was introduced in [2-7], and particularly [6,7] represented mutual magnetic coupling between sections in a single winding. Moreover, [8-14] designed a two-winding model with mutual magnetic coupling. However, although three-winding transformers are widely used in practice, few three-winding transformer models have been studied. A comprehensive three-winding model with mutual magnetic coupling is required for credible simulations with the model. In this sense, this work focuses on a three-winding transformer model.

A high-frequency transformer model with lumped $\mathrm{R}, \mathrm{L}$, and $\mathrm{C}$ components is usually modeled by circuit analysis programs, such as MATLAB/Simulink, electromagnetic transients program (EMTP), or PSpice [12]. In addition, the state-space method has also been used to analyze the circuit $[11,15]$. The state-space method is an efficient approach that calculates the transfer function of the model and conducts frequency response analysis (FRA). 
The R, L, and C components of a high-frequency transformer model cause resonance phenomena, and FRA results sufficiently reflect this phenomena. The typical FRA for power transformers is sweep frequency response analysis (SFRA), which measures frequency responses ranging from approximately $20 \mathrm{~Hz}$ to $20 \mathrm{MHz}$. The SFRA is commonly used for transformer fault diagnosis based on distortion observation. In [3], the normal and fault states were compared using FRA, and the authors of [4] simulated the FRA on the high-frequency transformer model by changing various parameters. Similarly, [8] observed the relationships between parameters and frequency responses and then compared the FRA results of normal and fault states. In [6], impulse tests and fast Fourier transform were conducted for the FRA. In [7], the authors used driving-point impedance for transformer parameter estimation. In [5,12-14,16-20], SFRA data was used to detect the deformation or fault of a power transformer. The core diagnosis based on SFRA was covered in [5]. In [12], the authors first observed the relationships between parameters and frequency response and then analyzed frequency response in fault conditions. In $[13,14,17,19]$, the SFRA was used to diagnose interturn faults such as short-circuit faults and winding deformation. The authors of [21] presented a comprehensive, detailed review of the transformer FRA, including test methods, objectives, structures, and results. In [5,7,9,10,14,17-20], methods that calculate magnetic deformation using structural or physical analysis were presented with the comparison of normal and fault states via graphs.

As aforementioned, frequency or magnetic analysis of power transformers can be used to detect transformer faults. In other words, modeling of a power transformer and parameter estimation using FRA is practicable because FRA results based on a highfrequency model represent transformer characteristics well. Therefore, this paper proposes a high-frequency transformer model and an efficient parameter estimation method based on SFRA data. Based on the high-frequency model, SFRA results are calculated and then compared with measured SFRA data. The parameters can be estimated to make the calculated SFRA results identical to the measured ones. Ultimately, the transformer model should reflect resonances in the frequency domain, and the state-space equations need to be developed for efficient FRA simulation.

Existing modeling methods require a long computation time and large amounts of data, including specific structural or physical data $[9-11,17,20]$. In $[9,10]$, the authors estimated transformer parameters by analyzing transformer structures and calculating the deformation of turns. The authors of [11,17] used the finite element method based on electromagnetics and structural mechanics data to model and analyze the transformer. In [20], 3D structures and schematic diagrams were used to design a high-frequency equivalent circuit of a transformer. The proposed method of this paper takes a shorter time to estimate transformer parameters than the previous works because the method uses simple SFRA data rather than detailed transformer structural and physical data.

The rest of this paper is as follows. In Section 2, a three-winding transformer model is proposed, and a parameter estimation method based on the model is introduced in Section 3. Then, Section 4 presents case studies with an actual $154 \mathrm{kV}$ single-phase threewinding transformer. Finally, the paper is concluded in Section 5.

\section{High-Frequency Transformer Model}

This section introduces the proposed high-frequency transformer model in detail. The high-frequency model has three windings that have magnetic coupling with each other. The equivalent circuit of the proposed model is presented in Section 2.1, and the state-space method is discussed in Section 2.2.

\subsection{Three-Winding Power Transformer Model}

The three-winding power transformer for the FRA is shown in Figure 1. The model has iterative structures with RLC sections. The symbols L and G represent the inductance and conductance of each winding turn, respectively. While the symbol $C$ in series represents the capacitance between winding turns, the symbol $\mathrm{C}$ in shunt is a capacitive air gap between 
a winding and the core or tank. The symbol $\mathrm{M}$ represents mutual inductance between windings. The first digit of subscripts represents the winding number, and its second digit denotes the section number of the winding. Note that the repetitive RLC structure generates quadratic resonance, including resonance and anti-resonance, which also appear in measured SFRA data.

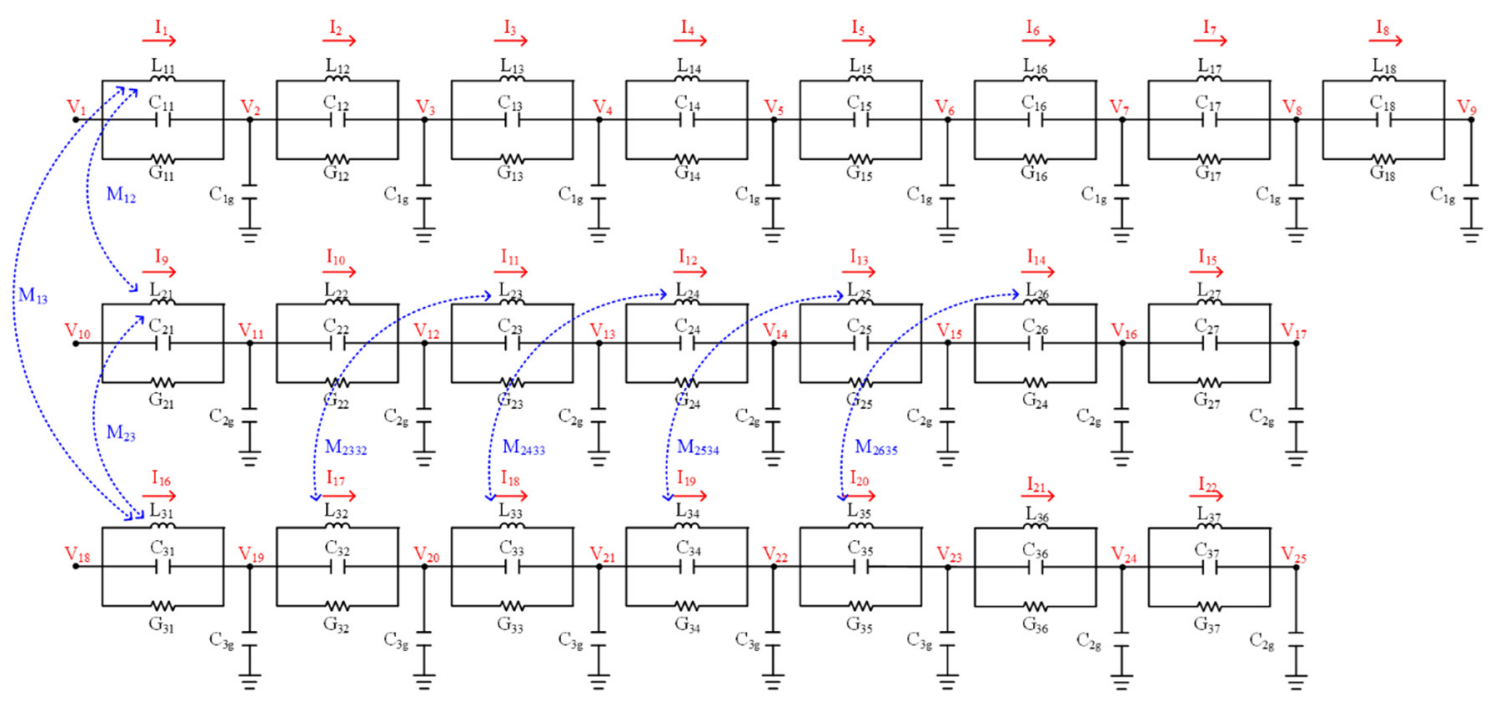

Figure 1. Single-phase three-winding transformer model.

\subsection{Power Transformer Model Using the State-Space Method}

Like Simulink or ATPDraw, programs are available to analyze the frequency response of the proposed model. These programs take considerable time to analyze the circuit. However, iterative processes occur to estimate parameters, so the long computation time is a critical drawback. Additionally, it is cumbersome to use these programs to create each circuit of the three-winding model to measure different SFRA configurations. Therefore, we build the state-space equations of the model to extract the transfer function. Then, the frequency response analysis result is calculated from the transfer function of each SFRA measuring scheme. The state-space method enables the operator to calculate the transfer function with internal model parameters, and the numerical analysis model extracts the frequency response graph faster.

Figure 2 shows the model that combined the proposed model in Figure 1 with the SFRA measuring device. The transformer parameters and state variables for the state-space method are represented in Figure 2.

For state variables, the voltage applied to each node is denoted as $\mathrm{V}$, and the current flowing through the inductor is denoted as I. State-space equations are represented using Kirchhoff's current law and Kirchhoff's voltage law by applying the defined state variables:

$$
\begin{gathered}
\dot{X}=A X+B V_{\text {in }} \\
Y=D X \\
X=\left[\begin{array}{c}
V \\
I
\end{array}\right], A=\left[\begin{array}{cc}
C^{-1} G & C^{-1} \Gamma \\
L^{-1} \Gamma^{T} & 0
\end{array}\right], B=\left[\begin{array}{c}
C^{-1} P \\
0
\end{array}\right]
\end{gathered}
$$

where $V_{\text {in }}$ is the input voltage for the SFRA, $\mathrm{P}$ is the matrix added to consider nodes connected by the input voltage, and $\Gamma$ is the matrix in which the direction of the induced 
current in Kirchhoff's current law is expressed as $-1,0$, and 1 . The transfer function of the state-space model can be obtained by Laplace transform:

$$
H(s)=\frac{Y(s)}{u(s)}=D(s I-A)^{-1} B
$$

With the SFRA measuring device, the transfer function of the input terminal is defined as $H_{\text {in }}(s)$, and the transfer function of the output terminal is defined as $H_{\text {out }}(s)$. In the case of the SFRA test connection shown in Figure 2, the first winding input terminal voltage is $V_{1}$ and the output terminal voltage is $V_{9}$. The transfer function can be obtained by:

$$
\begin{gathered}
H_{\text {in }}(s)=\frac{V_{1}(s)}{V_{\text {in }}(s)}, H_{\text {out }}(s)=\frac{V_{9}(s)}{V_{\text {in }}(s)} \\
H(s)=\frac{H_{\text {out }}(s)}{H_{\text {in }}(s)}=\frac{V_{9}(s) / u(s)}{V_{1}(s) / u(s)}=\frac{V_{9}(s)}{V_{1}(s)}
\end{gathered}
$$

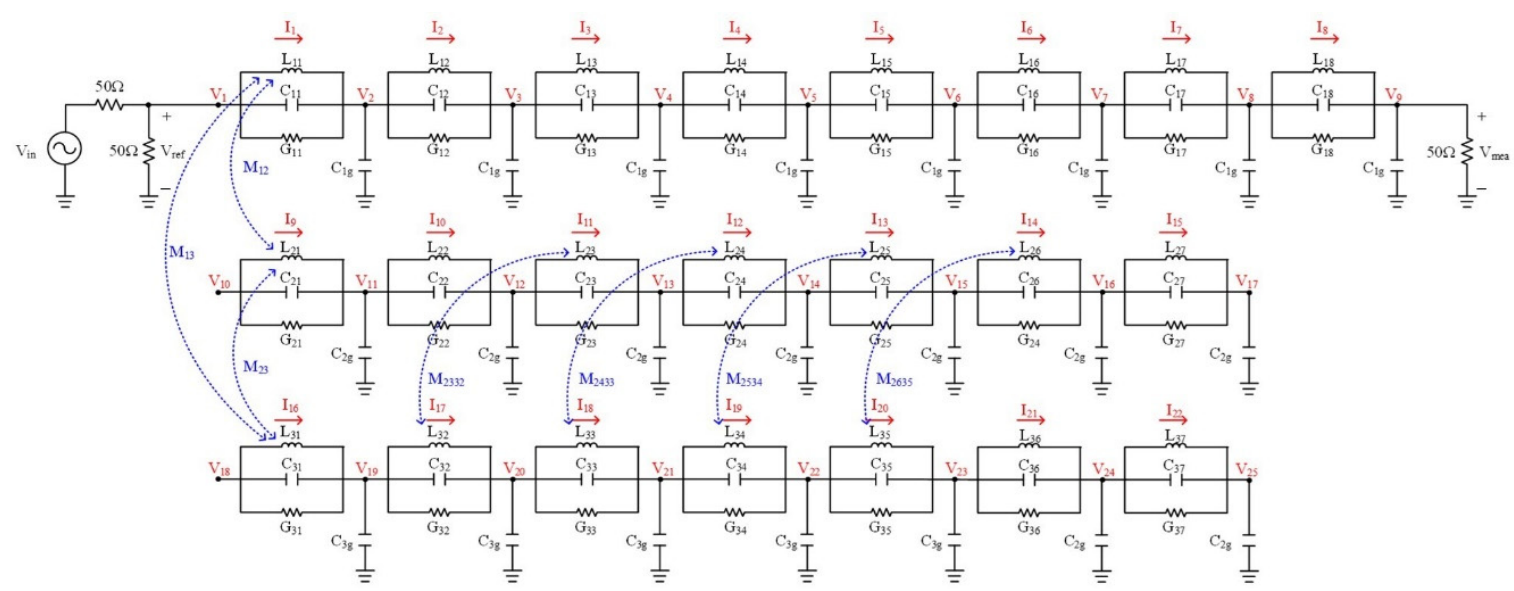

Figure 2. Single-phase three-winding transformer model with an SFRA measuring device for the first winding measurement open-circuit test.

\section{Parameter Estimation Process Based on SFRA}

The process of estimating parameters via matching the measured and simulated SFRA data is summarized in Figure 3.

The measured SFRA of the real transformer is compared with the simulated frequency response of the proposed transformer model, and the estimation process aims to improve the consistency of the two SFRA. The process begins from the appropriate initial parameters of the proposed model, which are fit to the comparison SFRA graph. If any three-winding transformer has SFRA data, the above parameter estimation process can be applied based on the proposed model, such as Figure 2.

The more winding sections in the transformer circuit model located to the right, the more the high-frequency response is involved. For the first section of the first winding, modifying $\mathrm{L}, \mathrm{C}$, and $\mathrm{G}$ values in that section affects the first resonance point of all six SFRA tests as other windings consider magnetic coupling. Therefore, a frequency response comparison is initiated in the first winding measurement open-circuit test. The first section parameters of the first winding should be corrected to align with the first resonance point of the first winding measurement open-circuit test. Besides, determining the ratio of the first, second, and third winding $L$ values, according to the ratio of the frequency response magnitude, allows the first resonance point of all first, second, and third winding opening tests to be aligned. 


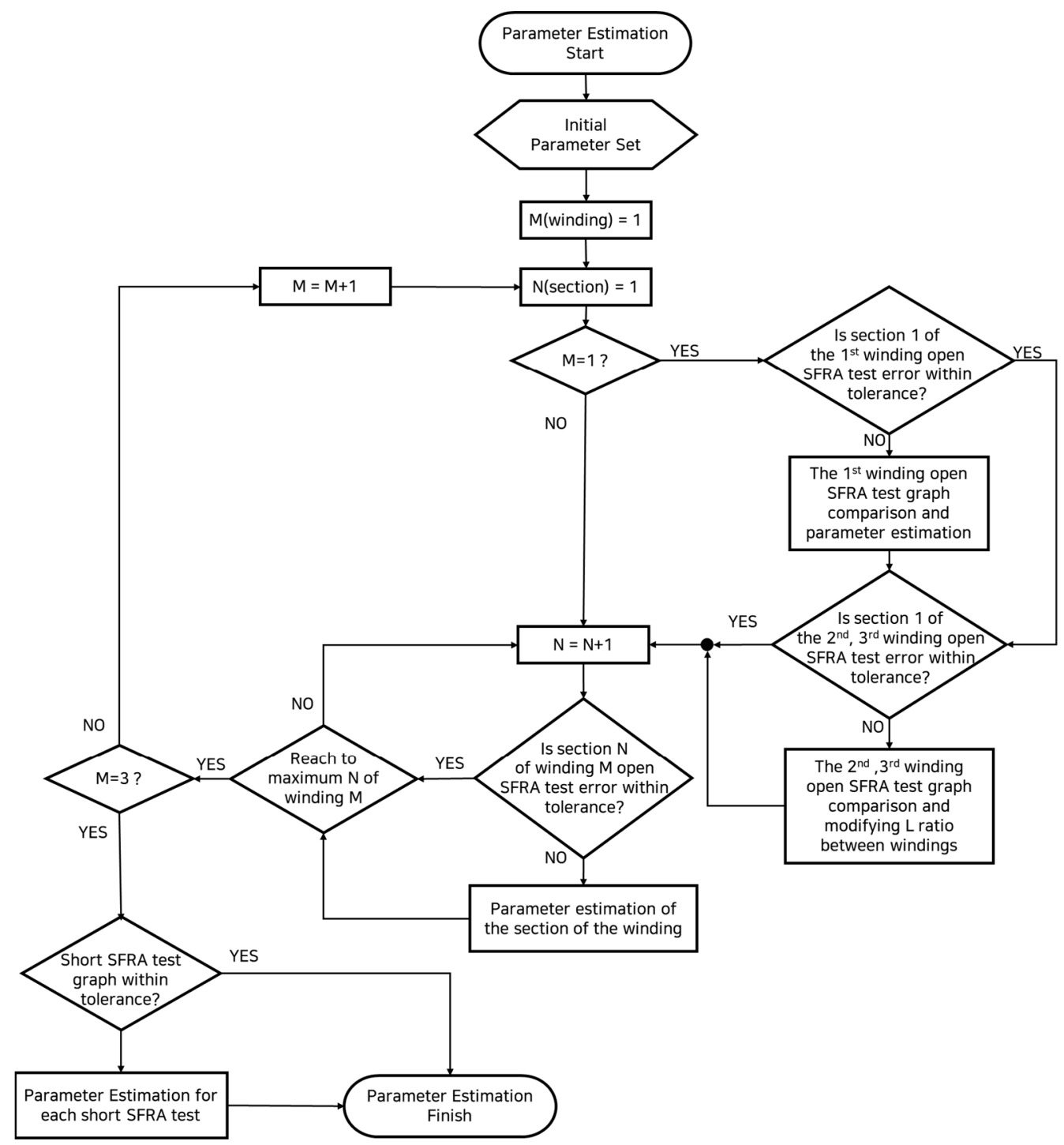

Figure 3. Transformer parameter estimation process.

Next, the parameters of the remaining sections, except for the magnetic coupling section, should be modified values for each section according to the resonant frequency and magnitude of each winding open-circuit test. For example, if the operator tries to align the third resonance point of the second winding, the operator should change the L, C, and $G$ values in the third section of the second winding and compare the SFRA graphs.

Finally, the last process is comparing SFRA short test results. The operator modifies the values of the mutual coupling coefficient $(\mathrm{k})$ and shunt capacitance $C_{g}$ to align the frequency response graph of the model with the actual SFRA data. The open-circuit test SFRA graph and the short test SFRA graph should be compared and selected to minimize the error between the two SFRA. The effect of each parameter on frequency response is summarized in Table 1. Based on Table 1, it is possible to estimate the transformer parameter by modifying the parameters of each section and comparing measured SFRA data and the simulated SFRA of the model. 
Table 1. Effects of transformer parameters on frequency response.

\begin{tabular}{|c|c|c|}
\hline Parameter & Change & Effects on Frequency Response \\
\hline \multirow{3}{*}{$\mathrm{L}$} & Increase & Resonance width wider \\
\hline & Decrease & Resonance width narrower \\
\hline & Resonance Frequency & $w_{0}=\frac{1}{\sqrt{L C}}$ \\
\hline \multirow[t]{2}{*}{$\mathrm{C}$} & Increase & Resonance width narrower \\
\hline & Decrease & Resonance width wider \\
\hline \multirow{2}{*}{ G } & Increase & Resonance peak blunter \\
\hline & Decrease & Resonance peak sharper \\
\hline $\mathrm{K}$ & $\begin{array}{l}\text { Increase } \\
\text { Decrease }\end{array}$ & Same as L effects \\
\hline$C_{g}$ & $\begin{array}{l}\text { Increase } \\
\text { Decrease }\end{array}$ & $\begin{array}{l}\text { Decrease the high-frequency magnitude } \\
\text { Increase the high-frequency magnitude }\end{array}$ \\
\hline
\end{tabular}

\section{Case Study}

According to the parameter estimation process in Figure 3, the proposed parameter estimation method first applies to one winding parameter and then to the other windings. For this parameter estimation, the effects of each parameter on frequency response are investigated. Then, estimation results for an integrated three-winding model are presented.

As mentioned in Section 2, the state equations should be constructed for efficient parameter estimation. After building state-space equations from the model, MATLAB is used to obtain the transfer function and perform the FRA. Then, parameters are estimated using the state-space equations.

As performance metrics, the root mean squared error (RMSE) and mean absolute error $(M A E)$ are used as follows:

$$
\begin{gathered}
\text { RMSE }=\sqrt{\frac{1}{N} \sum_{i=1}^{N}\left(20 \log _{10} y_{s}-20 \log _{10} y_{m}\right)^{2}} \\
M A E=\frac{1}{N} \sum_{i=1}^{N}\left|20 \log _{10} y_{s}-20 \log _{10} y_{m}\right|
\end{gathered}
$$

where $N$ is the number of frequency samples, and $y_{s}$ and $y_{m}$ denote the magnitude of simulated and measured SFRA, respectively.

\subsection{Single-Winding Model Parameter Estimation of a Single-Phase Transformer}

This section presents the estimation results of single-winding model parameters of a single-phase transformer, using SFRA data measured from an open-circuit test of a $154 \mathrm{kV}$ single-phase transformer manufactured by LS Electric. To determine the effectiveness of frequency response for each parameter in the transformer when only a single winding is presented, the parameters of other windings and mutual coupling are not considered. The single-winding model makes it relatively easy to estimate parameters because it has repetitive structures of unit sections without mutual coupling. After the parameter estimation of the single-winding model, the SFRA results of the open-circuit test simulation are compared with those of the actual field test, as shown in Figure 4.

Quadratic resonances occur in each section of the single-winding model. There are eight anti-resonances and seven resonances within the frequency range shown in Figure 4. The model parameters are estimated by resonance frequency, width, and magnitude at each section based on Table 1. From the full frequency range of $120 \mathrm{rad} / \mathrm{s}$ to $1 \mathrm{Mrad} / \mathrm{s}$ in Figure 4, the RMSE is $2.5881 \mathrm{~dB}$, and the MAE is $1.8446 \mathrm{~dB}$. For $154 \mathrm{kV}$ transformers, frequency responses from $20 \mathrm{kHz}$ to $20 \mathrm{MHz}$ are utilized for fault verification using SFRA [16]. However, the frequency response in the high-frequency domain is not important when simulating a transformer model to the power system. When using SFRA data for 
transformer faults detection, the frequency range below $2 \mathrm{kHz}$ determines the deformation and movement of the transformer steel core, and the $2 \mathrm{kHz}$ to $20 \mathrm{kHz}$ range determines the deformation and movement of the windings in the transformer. The $20 \mathrm{kHz}$ to $2 \mathrm{MHz}$ range is the discriminant range for transformer structures, and frequencies greater than $2 \mathrm{MHz}$ are the frequency response area according to the connection and ground state of the SFRA measuring instrument [22]. Thus, the target in this simulation and modeling is an iron core and magnetic coupling between transformer windings. Therefore, only the frequency domain below $20 \mathrm{kHz}$ is an important range in the proposed method that uses SFRA. As a result, the RMSE is $0.7127 \mathrm{~dB}$ and MAE is $0.5569 \mathrm{~dB}$ in the frequency range below $20 \mathrm{kHz}$.

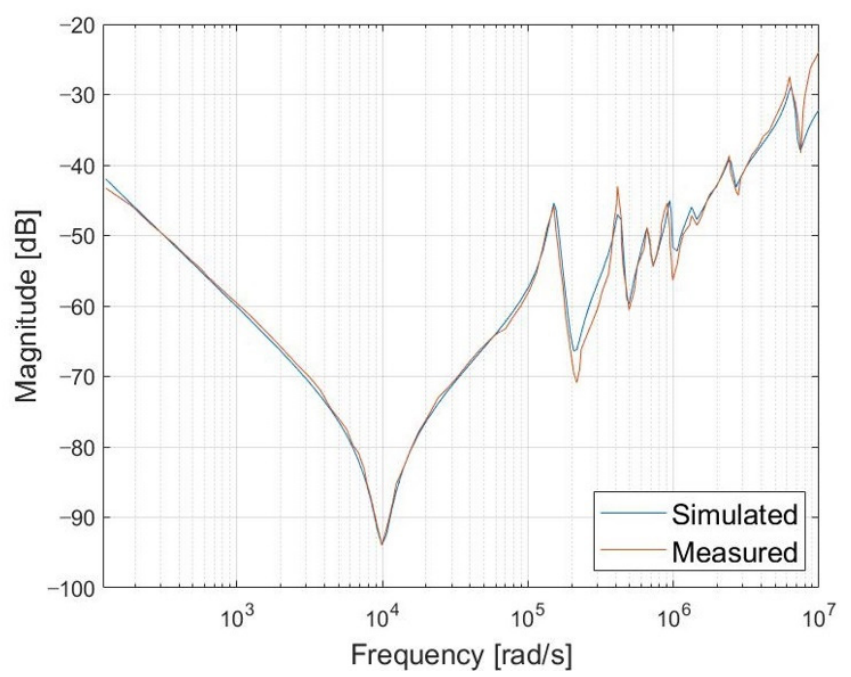

Figure 4. Comparison of model SFRA and measured SFRA (single-winding model, first winding SFRA, open-circuit test).

While the existing FEM method [11] resulted in the MAE of $1.9782 \mathrm{~dB}$ for a singlewinding model in the frequency range from $100 \mathrm{~Hz}$ to $1 \mathrm{MHz}$, the MAE in the proposed method was $1.4654 \mathrm{~dB}$ in the same range of frequency. This comparison implies that the proposed method can estimate parameters more accurately than the FEM method.

\subsection{Three-Winding Model Parameter Estimation of a Single-Phase Transformer}

In this section, the methodology used in the parameter estimation of the singlewinding model is applied to a three-winding integrated transformer model. For the parameter estimation of the three-winding model presented in Figure 2, six frequency response tests should be implemented as described in Table 2. In the end, the estimated model should meet all six tests at once.

Table 2. Test number and measuring scheme of transformer SFRA.

\begin{tabular}{cc}
\hline Test & Measurement Method \\
\hline 1 & First winding measurement, open circuit test \\
2 & First winding measurement, second winding short-circuit test \\
3 & First winding measurement, third winding short-circuit test \\
4 & Second winding measurement, third winding short-circuit test \\
5 & Second winding measurement, open circuit test \\
6 & Third winding measurement, open circuit test \\
\hline
\end{tabular}

Figure 5 presents the parameter estimation result of the three-winding model, indicating that the simulated SFRA curves correspond well with the measured one for the first winding. However, for the second and third windings, the parameter estimation results are not good below $1000 \mathrm{rad} / \mathrm{s}$. This is largely because the first winding parameters were first 
estimated, and then the second and the third ones were done sequentially; note that the three windings are coupled magnetically. That is, estimation results were biased towards increasing the estimation accuracy of the first winding parameters. These estimation errors can be reduced by more sophisticated structures of RLC sections and thorough estimation than the proposed approach, which is a target of future research.

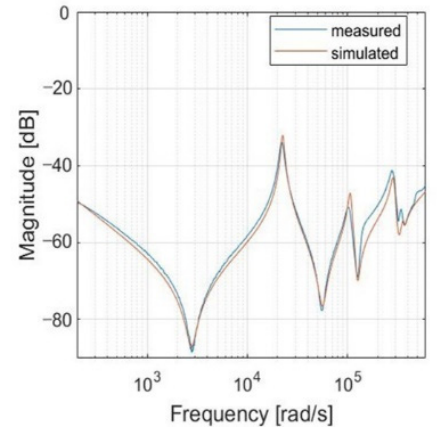

(a)

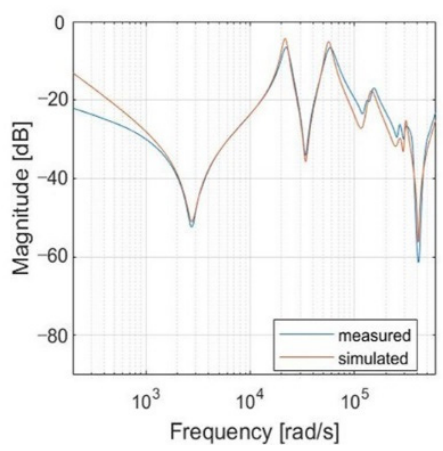

(b)

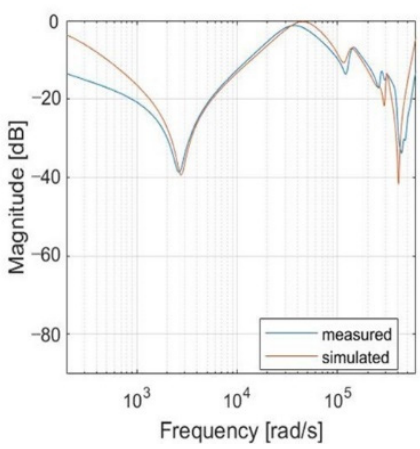

(c)

Figure 5. Comparison of simulated SFRA open-circuit test and measured SFRA open-circuit test in integrated three-winding model: (a) the first winding SFRA open-circuit test; (b) the second winding SFRA open-circuit test; and (c) the third winding SFRA open-circuit test.

Table 3 lists the RMSE and MAE of SFRA open-circuit tests for the entire frequency range of SFRA, and Table 4 presents the RMSE and MAE of the same tests for the frequency range under $20 \mathrm{kHz}$. It can be observed from Tables 3 and 4 that the proposed method can provide more accurate estimation results under $20 \mathrm{kHz}$, where the deformation and movement of steel cores and windings are dominant factors for forming SFRA curves.

Table 3. RMSE and MAE comparison between measured and simulated SFRA for the entire frequency range.

\begin{tabular}{cccc}
\hline Test & $\mathbf{1}$ & $\mathbf{5}$ & $\mathbf{6}$ \\
\hline RMSE $(\mathrm{dB})$ & 2.5456 & 5.3537 & 10.6372 \\
MAE $(\mathrm{dB})$ & 1.8071 & 3.4449 & 6.3873 \\
\hline
\end{tabular}

Table 4. RMSE and MAE comparison between measured and simulated SFRA under $20 \mathrm{kHz}$.

\begin{tabular}{cccc}
\hline Test & $\mathbf{1}$ & $\mathbf{5}$ & $\mathbf{6}$ \\
\hline RMSE $(\mathrm{dB})$ & 1.4387 & 4.0047 & 4.7644 \\
MAE $(\mathrm{dB})$ & 1.2475 & 2.6397 & 3.4610 \\
\hline
\end{tabular}

\section{Conclusions}

This paper proposes a new parameter estimation scheme for the three-winding transformer model, using an SFRA test, which has widely been used to detect transformer deformation or short-circuit conditions. For the estimation, a single model of a threewinding transformer, which is comprised of a proper combination of repetitive RLC sections, is created and used. The proposed estimation method has the following major contribution. The traditional parameter estimation of transformers is based on the physical and structural information of transformers, which requires a thorough analysis of their electromagnetics and structural mechanics. In comparison, the SFRA-based method uses simple SFRA measurement data, which reflect physical characteristics of transformers, and then estimates circuit parameters directly. In the end, the proposed approach does not need any measured magnetics data or transformer structural data, and therefore the estimation process can be quick and straightforward. Moreover, unlike the previous works 
considering single- or two-winding models only, this work dealt with a three-winding transformer model. For validation, actual field SFRA data of a $154 \mathrm{kV}$ three-winding power transformer was tested, and then transformer model parameters were estimated. Finally, it can be concluded that the transformer parameter estimation was successful since SFRA data simulated with the estimated model almost matches the measured data.

The estimation developed in this work can be applied to any transformer model. Ultimately, the transformer model should be modified with a proper combination of RLC sections and mutual inductances, which is then followed by new SFRA tests. Then, based on the test measurement data, transformer parameters can be estimated.

For the stability and efficiency of the power grid, it is important to simulate a power device on a computer to model power apparatuses and estimate their parameters. Based on our new model and parameter estimation method for transformers, we expect to contribute to the advancement of power system operational technologies through the additional impulse test of transformers or other power facility linkages. Advanced technologies, such as optimization and parameter estimation through machine learning, will further improve the parameter estimation accuracy of transformer models.

Author Contributions: Conceptualization, Y.Y., S.J. and S.C.; Data curation, Y.Y. and S.J.; Funding acquisition, S.C.; Investigation, Y.Y., J.C., and S.C.; Methodology, Y.Y., S.J., and S.C.; Resources, J.C., S.J., and Y.-G.K.; Software, Y.Y., Y.S., and S.C.; Supervision, S.J. and S.C.; Validation, S.J. and Y.-G.K.; Visualization, Y.Y. and Y.S.; Writing-original draft, Y.Y. and S.C.; Writing-review \& editing, Y.Y. and S.C. All authors have read and agreed to the published version of the manuscript.

Funding: This research was supported in part by LS Electric Co., Ltd., in part by the KEPCO Research Institute under the project entitled by "A Research of Advanced Distribution Planning System for Mid-long term(R20DA16)," and in part by the Basic Research Program through the National Research Foundation of Korea(NRF) funded by the MSIT(No. 2020R1A4A1019405).

Conflicts of Interest: The authors declare no conflict of interest.

\section{References}

1. Bjerkan, E. High Frequency Modeling of Power Transformers. Stresses and Diagnostics. Ph.D. Thesis, Department for Electrical Power Engineering, Norwegian University of Science and Technology, Trondheim, Norway, 2005.

2. Ding, Q.; Yao, Y.; Wang, B.; Fu, J.; Zhang, W.; Zeng, C.; Li, X.; Valtcehv, S. A modified lumped parameter model of distribution transformer winding. Glob. Energy Interconnect. 2020, 3, 158-165. [CrossRef]

3. Ryder, S.A. Diagnosing transformer faults using frequency response analysis. IEEE Electr. Insul.Mag. 2003, 19, 16-22. [CrossRef]

4. Abu-Siada, A.; Hashemnia, N.; Islam, S.; Masoum, M.S.A. Impact of transformer model parameters variation on FRA signature. In Proceedings of the 2012 22nd Australasian Universities Power Engineering Conference (AUPEC), Bali, Indonesia, 26-29 September 2012.

5. Smugala, D.; Bonk, M.; Ziemski, R. Single-phase magnetic cores' faults diagnosis using FRA approach. Measurement 2018, 114, 428-435. [CrossRef]

6. Paulraj, T.; Kishan, S.P.; Dhana, S.P. Modeling and location of faults in power transformer using Transfer Function and Frequency Response Analysis. In Proceedings of the 2014 IEEE International Conference on Advanced Communications, Control and Computing Technologies, Ramanathapuram, India, 8-10 May 2014; pp. 83-87.

7. Patel, S.; Derwal, A.; Doshi, S.; Rajendra, S.K. Utilising Genetic Algorithm and Driving Point Impedance Data to Synthesize High Frequency Circuit Model of Power Transformer Winding. In Proceedings of the 2018 5th International Conference on Signal Processing and Integrated Networks (SPIN), Noida, India, 22-23 February 2018.

8. Alsuhaibani, S.; Khan, Y.; Beroual, A.; Malik, N.H. A review of frequency response analysis methods for power transformer diagnostics. Energies 2016, 9, 879. [CrossRef]

9. Karimifard, P.; Gharehpetian, G.B. A new algorithm for localization of radial deformation and determination of deformation extent in transformer windings. Electr. Power Syst. Res. 2008, 78, 1701-1711. [CrossRef]

10. Rahimpour, E.; Christian, J.; Feser, K.; Mohseni, H. Transfer function method to diagnose axial displacement and radial deformation of transformer windings. IEEE Trans. Power Deliv. 2003, 18, 493-505. [CrossRef]

11. Abeywickrama, N.; Serdyuk, Y.V.; Gubanski, S.M. High-Frequency Modeling of Power Transformers for Use in Frequency Response Analysis (FRA). IEEE Trans. Power Deliv. 2008, 23, 2042-2049. [CrossRef]

12. Mariprasath, T.; Kirubakaran, V. Power transformer faults identification using SFRA. Int. J. Sci. Eng. Res. 2014, 5518, 81-87.

13. Wu, Z.; Zhou, L.; Lin, T.; Zhou, X.; Wang, D.; Gao, S.; Jiang, F. A New Testing Method for the Diagnosis of Winding Faults in Transformer. IEEE Trans. Instrum. Meas. 2020, 69, 9203-9214. [CrossRef] 
14. Devadiga, A.; Harid, N.; Griffiths, H.; Sayari, N.A.; Barket, B.; Jayaram, S.; Ikedam, H.; Koshizuka, T.; Taniguchi, Y. Winding turn-to-turn short-circuit diagnosis using FRA method: Sensitivity of measurement configuration. IET Sci. Meas. Technol. 2018, 13, 17-24. [CrossRef]

15. Secue, J.R.; Mombello, E. Sweep frequency response analysis (SFRA) for the assessment of winding displacements and deformation in power transformers. Electr. Power Syst. Res. 2008, 78, 1119-1128. [CrossRef]

16. Senobari, R.K.; Sadeh, J.; Borsi, H. Frequency response analysis (FRA) of transformers as a tool for fault detection and location: A review. Electr. Power Syst. Res. 2018, 155, 172-183. [CrossRef]

17. Behjat, V.; Vahedi, A.; Setayeshmehr, A.; Borsi, H.; Gockenbach, E. Identification of the most sensitive frequency response measurement technique for diagnosis of interturn faults in power transformers. Meas. Sci. Technol. 2010, 21, 075106. [CrossRef]

18. Cutten, M.; Korenciak, D.; Kucera, M.; Janura, R.; Glowacz, A.; Kantoch, E. Fequency and time fault diagnosis methods of power transformers. Meas. Sci. Rev. 2018, 18, 162-167.

19. Gutten, M.; Janura, R.; Sebok, M.; Korenciak, D.; Kucera, M. Measurement of short-circuit effects on transformer winding with SFRA method and impact test. Metrol. Meas. Syst. 2016, 23, 521-529. [CrossRef]

20. Abu-Siada, A.; Radwan, I.; Abdou, A.F. 3D approach for fault identification within power transformers using frequency response analysis. IET Sci. Meas. Technol. 2019, 13, 903-911. [CrossRef]

21. Javed, M.; Aftab, H.; Qasim, M.; Sattar, M. RLC circuit response and analysis (using state space method). IJCSNS Int. J. Comput. Sci. Netw. Secur. 2008, 8, 48-54.

22. IEC 60076-18:2012, Power Transformers-Part 18: Measurement of Frequency Response. Available online: https:/ / webstore.iec. ch/publication/597 (accessed on 2 July 2021). 